\title{
Delayed response to abnormal lithium results is no longer necessary
}

\author{
J. R. King and N. J. Birch
}

\begin{abstract}
A survey of one year's lithium results for a health district of 170000 disclosed unacceptable delays in checking abnormally high values. Only $17 \%$ of moderately elevated lovels were rechecked within a week. The problem was most marked with patients monitored in general practice, but one particularty high result in a patient monltored in psychiatric out-patients remained unchecked for over three weeks as a result of poor communication between general practitioner and poychiatrist. A trial of an on-the-spot monitoring service using new technology has simplified procedures and reduced to zero the number of results taking over a week to check.
\end{abstract}

Lithium remains unsurpassed for the prophylaxis of most cases of recurrent affective disorder (Schou, 1992), and is increasingly used for shorter-term indications such as augmenting antidepressants or controlling aggression (de Montigny, 1994). The average general psychiatrist will have responsibility for perhaps 30 to 40 patients on long-term lithium. Historically, however, enthusiasm for using lithium has not always been matched by a sober respect for its toxicity, as a result of which its reputation has suffered wide swings of attitude over the years, and its practitioners have suffered from significant litigation.

Efficient monitoring is therefore extremely important, but previous papers in the Bulletin have drawn attention to the inconsistency with which it is still carried out. Myers \& Hallworth (1996b) noted an apparent paradox of unnecessarily frequent testing in combination with a failure to take heed of abnormal results, while Ryman (1997), in a two-year study, found that only one-third of patients were adequately monitored. These issues have been highlighted by recent critical reviews of lithium's risks in relation to its evidence base (Cookson, 1997; Moncrieff, 1997). The present study was designed to examine in more detail how promptly abnormal results are acted upon in a district service, and whether any deficiencies can be remedied.

\section{The study}

All lithium results from the laboratory of a district general hospital serving a population of 170000 were scrutinised over a one-year period. Abnormally high results were categorised as 'amber alert' if they fell into the range 1.20 to $1.49 \mathrm{mmol} / \mathrm{l}$; these would be expected to require prompt rechecking. Results of $150 \mathrm{mmol} / 1$ or above were designated 'red alert' as urgent action would normally be expected.

In all cases, the test-retest interval was noted alongside the category of doctor (psychiatrist. hospital doctor, general practitioner (GP)) ordering the test, and in the case of the red-alert results the case notes were examined in detail to determine the sequence of events.

\section{Findings}

\section{Frequency of abnormal levels}

There were a total of 955 results from testing 294 patients: about two-thirds were ordered by psychiatrists, just less than one-third by GPs and a small number by hospital doctors. Twentyfour (or $2.5 \%$ ) of these results were abnormally high, and tests ordered by GPs were twice as likely to be high than those ordered by psychiatrists, a trend which did not, however, reach significance. There were 18 results in the amberalert category and six in the red-alert group; the latter were mainly ordered by hospital doctors.

\section{Speed of response}

Amber alert As shown in Table 1, only $17 \%$ of all doctors rechecked the amber-alert results within a week, by one month $39 \%$ had been rechecked, and even after three months the figure had only risen to $69 \%$. Psychiatrists tended to check results more promptly than GPs, none of whom succeeded in rechecking within a week.

Red alert Of the six results in this category, four were accounted for by two patients who took overdoses. Both drew attention to what they had 
Table 1. Speed of rechecking 'amber-alert' results

\begin{tabular}{llll}
\hline & \multicolumn{2}{l}{$\begin{array}{l}\text { Recheck of amber-alert results ordered } \\
\text { by: }\end{array}$} \\
\cline { 2 - 4 } $\begin{array}{l}\text { Cumulative } \\
\text { number }\end{array}$ & All doctors & $\begin{array}{l}\text { General } \\
\text { practitioners Psychiatrists }\end{array}$ \\
\hline Up to 1 week & $3(17 \%)$ & 0 & $3(30 \%)$ \\
Up to 1 month & $7(39 \%)$ & $1(13 \%)$ & $5(50 \%)$ \\
Up to 3 months & $12(69 \%)$ & $3(38 \%)$ & $9(90 \%)$ \\
Total number & 18 & 8 & 10 \\
\hline
\end{tabular}

done and were treated immediately, the very high ( $>3 \mathrm{mmol} / \mathrm{l}$ ) initial lithium levels being rechecked within 24 hours and rechecked again within a day or two.

In another case, a patient attending a day hospital developed a level of $1.60 \mathrm{mmol} / 1$ as a result of an interaction of lithium with ibuprofen. There was a four-day delay in reporting this result to clinicians by which time the patient was already ill with toxicity.

The final case involved initiation of lithium by a GP under the out-patient direction of a psychiatrist. The psychiatrist requested the GP to check the level but there was a lack of clarity as to who should be informed of the results. The psychiatrist did not learn of routine results until three weeks after testing, and was unable to counsel the patient about the significance of a level of $1.54 \mathrm{mmol} / \mathrm{l}$. He found out about this only when retrospectively informed by the patient, 25 days later. The patient recalled having been telephoned about the high result at the time, but was offered no advice on what to do.

\section{Comment}

Extensive evidence points to the need to avoid toxicity, if lithium is to be safely used long-term (Schou, 1988). Ideally, all lithium levels of $1.2 \mathrm{mmol} / 1$ or above should be swiftly dealt with by interviewing the patient and enquiring about dietary changes, drug interactions and other risk factors. At the very least the level should be checked to make sure that it is not a rogue result (caused for example by accidental taking of an extra dose, or by timing errors), and to determine whether the level is rising or falling. With the system commonly in use at present, there are certain inevitable delays imposed by transportation of samples, and laboratory turn around time, but allowing for this it would be reasonable to expect a recheck within a week in all amberalert cases. The results fall profoundly short of this.

No GPs and only a third of psychiatrists had rechecked levels within a week. After three months, most doctors had certainly managed to order another test, but bearing in mind that the routine monitoring interval is between three and six months, a recheck would quite probably have been carried out by this time in any case. The unsystematic pattern of monitoring closely mirrors that found by Ryman (1997) who noted that elevated results were largely ignored.

In the red-alert category it was only a matter of luck that the outcomes were not more serious. The two overdose patients reported immediately what they had done, which may not always be the case, indeed one similar case identified by Myers \& Hallworth (1996a) died as a result, despite dialysis. The drug interaction patient fortunately discontinued her ibuprofen spontaneously.

The out-patient whose level of $1.54 \mathrm{mmol} / \mathrm{l}$ was entirely missed by the psychiatrist, illustrates the confusion that can arise where monitoring is jointly managed by psychiatrist and general practitioner, each seeing the patient at different times. Results requested by one may be returned to the other by mistake, each doctor may assume erroneously that the other is carrying out specific checks, and the patient may be given conflicting advice.

\section{Further action: introduction of in-clinic ion selective monitoring}

The customary response to deficient lithium monitoring and the one reiterated by Myers $\&$ Hallworth (1996a). Peet \& Harvey (1991) and others, is to emphasise the value of education. While this cannot be disputed, there is an inherent defect in conventional laboratory monitoring caused by imperfect hospital transport and communications, and sadly this can defeat the most well intentioned efforts.

On-the-spot monitoring via the ion selective electrode is a well-validated method which overcomes these practical problems and was instituted by J. R. K., initially for a trial period. The portable instrument is user-friendly and gives an instantaneous lithium read-out as part of the consultation (King et al, 1991; Birch et al. 1992).

All lithium results were scrutinised as before to detect abnormal readings during the first six months of using the new method, and compared with the previous period of six months conventional monitoring. Only one result higher than $1.20 \mathrm{mmol} / 1$ was detected out of a total of 98 estimations over the six months following introduction of the clinic-based method. This was a reading of $1.38 \mathrm{mmol} / 1$, which was rechecked within a week. In the previous six-month period there were 76 lithium estimations of which, again, only one was abnormal at $1.25 \mathrm{mmol} / 1$. 
This result, however, had remained unchecked for three weeks.

\section{Recommendation}

Optimal, cost-effective use of in-clinic monitoring requires the establishment of dedicated lithium clinics where as many patients as possible attend. Our experience is that these clinics are best held at weekly intervals. The need for a blood check is evaluated on the clinical state of the patient as well as on the length of time since the last test. If the result is abnormal, corrective action may be taken straight away, and the results of the action checked the following week by which time the lithium level will have restabilised. The model, which we have now adopted permanently, provides complete flexibility and enables resistant patients to be more closely monitored on higher levels. Other patients may only need to be seen very infrequently unless a problem occurs unexpectedly.

\section{References}

Birch. N. J., Freeman, M.. Philups, J., et al (1992) The lithium ion selective electrode and its use in the lithium clinic: real time monitoring of plasma lithium. Lithium. 3. 133-137.
Cookson, J. (1997) Lithium: balancing risks and benefits. British Joumal of Psychiatry. 171, 120-124.

DE MONTIGNY, C. (1994) Lithium addition in treatmentresistant depression. International Clinical Psychopharmacology, 9 (suppl. 2), 31-35.

KING, J. R., PHILLIPS, J. D.. JUDGE, R., et al (1991) Instant lithium monitoring. Psychiatric Bulletin. 16. 138-139.

MONCRIEFF, J. (1997) Lithium: evidence reconsidered. British Journal of Psychiatry. 171. 113-119.

MYERS. D. H. \& HALLWORTH. M. J. (1996a) An investigation of high lithium concentrations. Psychiatric Bulletin, 20. 331-333.

- \& - (1996b) An investigation into lithium monitoring. Psychiatric Bulletin. 20, 333-334.

PEET, M. \& HARVEY, N. S. (1991) Lithium maintenance: a standard education programme for patients. British Journal of Psychiatry. 168, 197-200.

RYMAN, A. (1997) Lithium monitoring in hospital and general practice. Psychiatric Bulletin. 21, 570-572.

SCHOU, M. (1988) Effects of long-term lithium treatment on kidney function: an overview. Journal of Psychiatric Research, 22. 287-296.

- (1992) Lithium prophylaxis in perspective. Pharmacopsychiatry, 25, 7-9.

*J. R. King, Consultant Psychiatrist, Worcestershire Community Trust and Honorary Senior Lecturer, University of Birmingham. Hill Crest Clinic, Quinney's Lane, Redditch B98 7WG and N. J. Birch, Emeritus Professor of Biomedical Science, University of Wolverhampton

*Correspondence

\title{
Users' needs and satisfaction with a community-based mental health service
}

\author{
George Ralston, Sarah Beesley and John Bogue
}

There has been an increasing move to involve consumers in the assessment of health services. Needs assessment and consumer satisfaction of a recently setup community mental health feam is described.

Following the NHS and Community Care Act of 1990 the Greater Glasgow Community and
Mental Health Services NHS Trust have quickly progressed to a community model of care following years of institution-based services. The teams take direct referrals primarily from general practitioners, although referrals can be made by social services and voluntary agencies. One of the first community mental health teams (CMHTs) set up was the Goldenhill CMHT which 